artelogie

\section{Artelogie}

Recherche sur les arts, le patrimoine et la littérature de l'Amérique latine

$10 \mid 2017$

Après le paysage : l'art, l'inscription et la représentation de la nature en Amérique latine aujourd'hui

\title{
Un encuentro con el páramo de Eisenband
}

\section{Miguel Iriarte}

\author{
(2) OpenEdition \\ Journals \\ Edición electrónica \\ URL: http://journals.openedition.org/artelogie/917 \\ DOI: $10.4000 /$ artelogie. 917 \\ ISSN: 2115-6395 \\ Editor \\ Association ESCAL \\ Referencia electrónica \\ Miguel Iriarte, «Un encuentro con el páramo de Eisenband », Artelogie [En línea], 10 | 2017, Publicado \\ el 05 abril 2017, consultado el 22 abril 2019. URL : http://journals.openedition.org/artelogie/917 ; DOI : \\ 10.4000/artelogie.917
}

Este documento fue generado automáticamente el 22 abril 2019.

Association ESCAL 


\title{
Un encuentro con el páramo de Eisenband
}

\author{
Miguel Iriarte
}

1 Hace algunos años conocí una carpeta con fotografías de Gabriel Eisenband. Pero antes de conocer esa carpeta, ya había visto yo, en el entorno de las redes sociales, algunas imágenes fotográficas de paisajes que me habían llamado la atención. Unos pertenecían a lugares en Colombia y otros eran de diferentes sitios en el mundo, y en ellos había visto algo que era mucho más de lo que puede alguien hallar por casualidad al manejar una cámara fotográfica.

2 Había en aquellas imágenes un acercamiento, una manera de entender la naturaleza, una ambición expresiva, que las piezas de esta carpeta que tenía ante mí me reactualizaban esas primeras impresiones y potenciaban nuevos impactos en mi sensorium que ahora me persuadían de estar en presencia de un fotógrafo que entendía la inmensa soledad de la naturaleza y estaba allí frente a ella como un testigo excepcional que nos la compartía, sin trucos tremendistas ni tretas tecnológicas, para que nosotros pudiéramos entender la dimensión de lo que está en peligro de perderse de forma irremediable.

3 Mi primera reacción ante la experiencia de conocer esas imágenes de Gabriel Eisenband fue la de proponerle de inmediato realizar una exposición en la sala alterna a nuestra galería de la Biblioteca Piloto del Caribe, en Barranquilla, Colombia, pero él, elusivo y difícil, se perdió del paisaje y no volví a tener noticias suyas.

4 Ahora llega a mis manos este proyecto editorial del Portafolio de Chingaza, que nos trae 16 fotografías de Gabriel Eisenband en las que, no sólo están corroboradas cada una de mis impresiones iniciales aquí expresadas, sino que en ellas se multiplican y ahondan los alcances que en algún momento fueron promesa en el trabajo fotográfico germinal de este nuevo defensor de la belleza que considera los páramos como "fábricas surtidoras de agua" que no han sido asumidos plenamente de manera artística, pero que también contienen y comunican esa alta y solemne soledad de los paisajes que nos pone en contacto con el misterio espiritual que nos infunde la poesía lograda en este caso a través de la fotografía. 
El Páramo de Chingaza, en los Andes colombianos, es de una importancia no sólo emblemática en términos ecológicos e hidrográficos, comoquiera que en él nacen importantes acuíferos que alimentan la naturaleza y los acueductos de muchos centros urbanos; sino que están vinculados a la historia, a los estudios naturalistas desde la Colonia y especialmente a gran parte de la mitología de las culturas precolombinas en el país; hay de él una interesante iconografía en el pasado, especialmente de ilustradores de la Expedición Botánica, que llega a ser muy representativa de la regiones interiores del país.

6 Sus 76.600 hectáreas, aunque protegidas por el sistema de Parques Nacionales de Colombia desde 1977, han sido a través de los tiempos depredadas por la irresponsabilidad de los gobiernos y por las consecuencias de la lucha armada entre el ejército y la guerrilla. Sin embargo, todavía hoy es un hermoso territorio con gran riqueza paisajística, como ésta que eleva Eisenband a la categoría de arte y para llamar también la atención acerca la alta necesidad de su respeto y preservación, para dejar constancia histórica de un nuevo momento de este templo de la naturaleza.

7 Estas fotografías son elocuentes, revelan el poder cuasi religioso del paisaje, pero también dejan en suspenso parte de un sentido que no alcanza a decirse del todo. Es algo que nos recuerda a lo que alguna vez decía la fotógrafa norteamericana Diane Arbus para referirse al alma humana: "Una fotografía es un secreto acerca de otro secreto: cuanto más cuenta, menos sabes".

Parque Naatural Chingaza, reservorio de agua de la ciudad de Bogota, 2011-2017

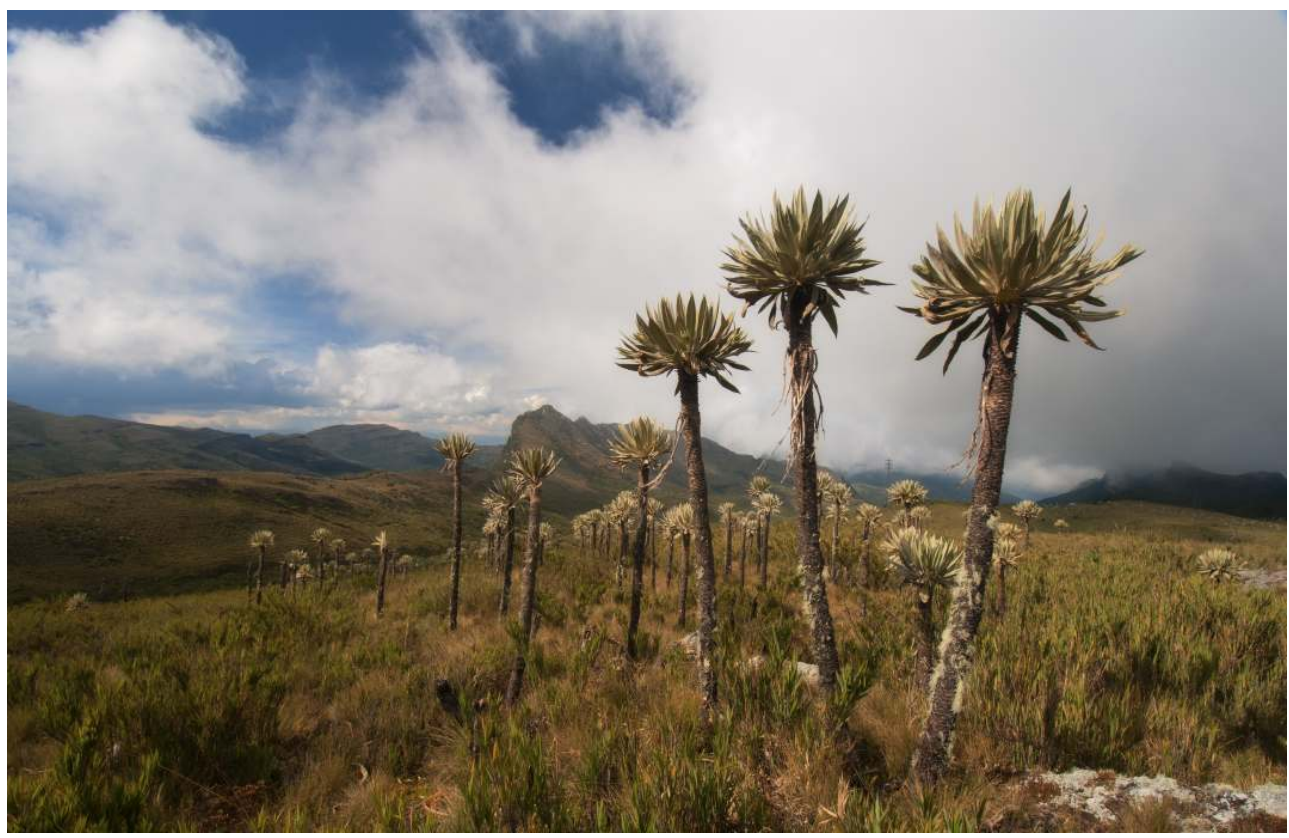


Parque Naatural Chingaza, reservorio de agua de la ciudad de Bogota, 2011-2017

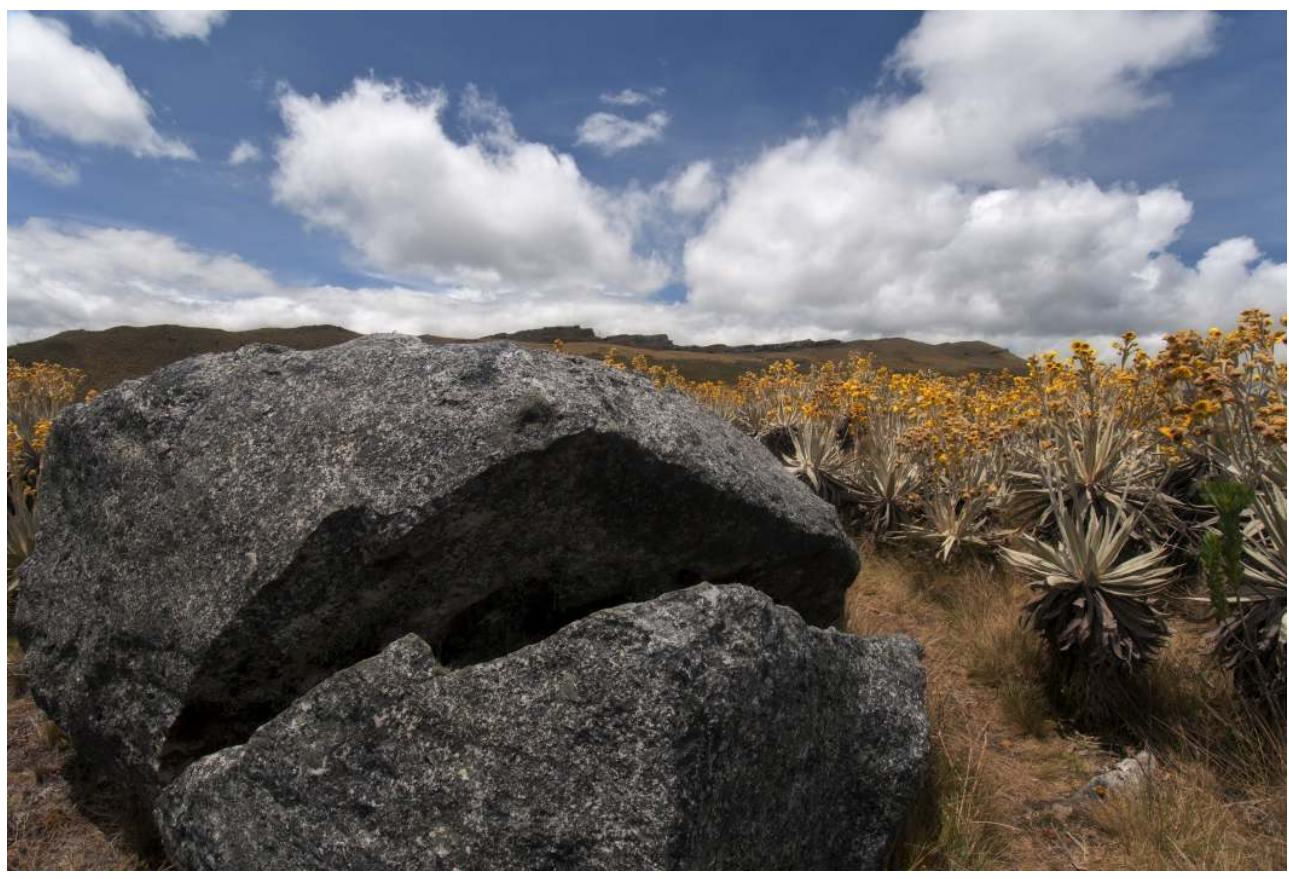

Parque Naatural Chingaza, reservorio de agua de la ciudad de Bogota, 2011-2017

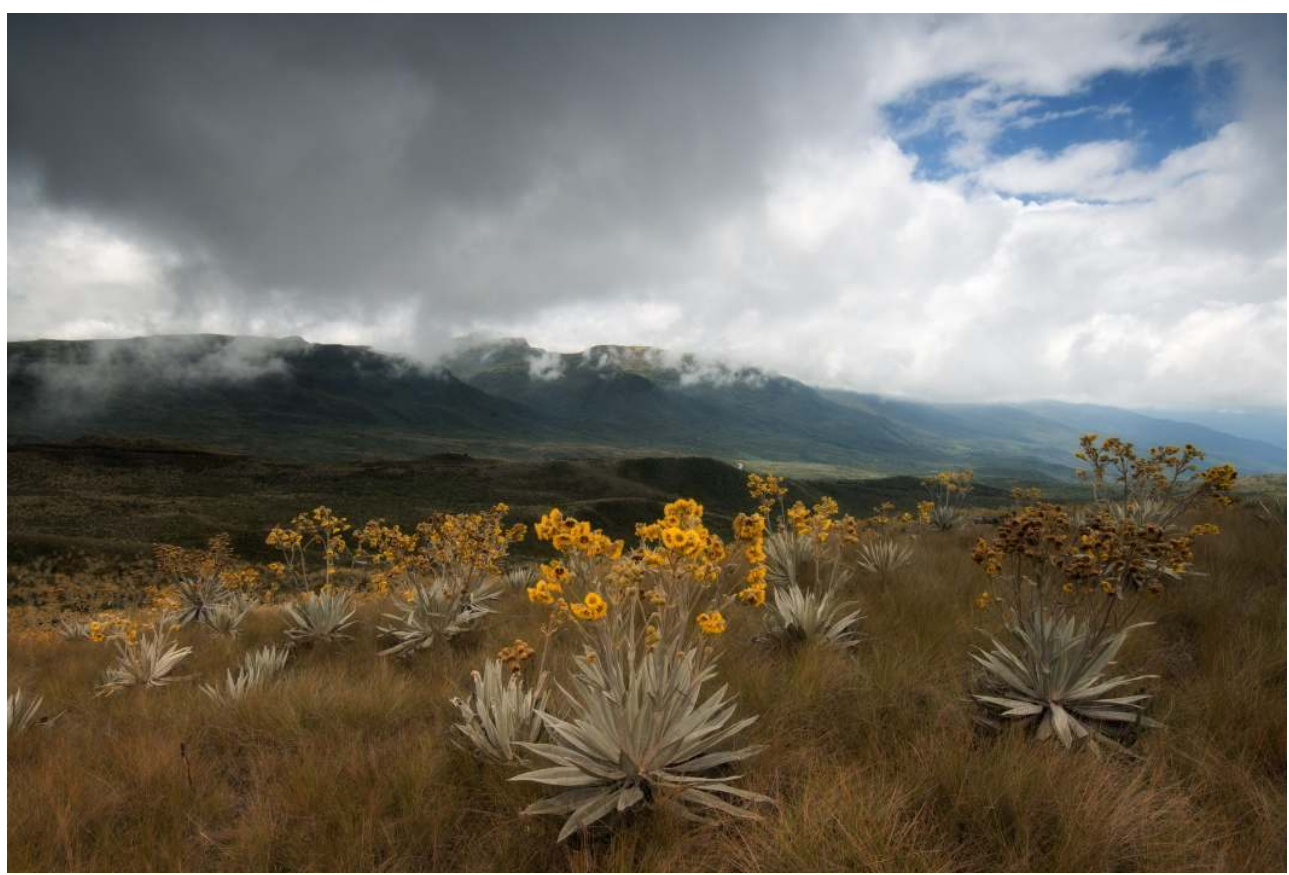


Parque Naatural Chingaza, reservorio de agua de la ciudad de Bogota, 2011-2017

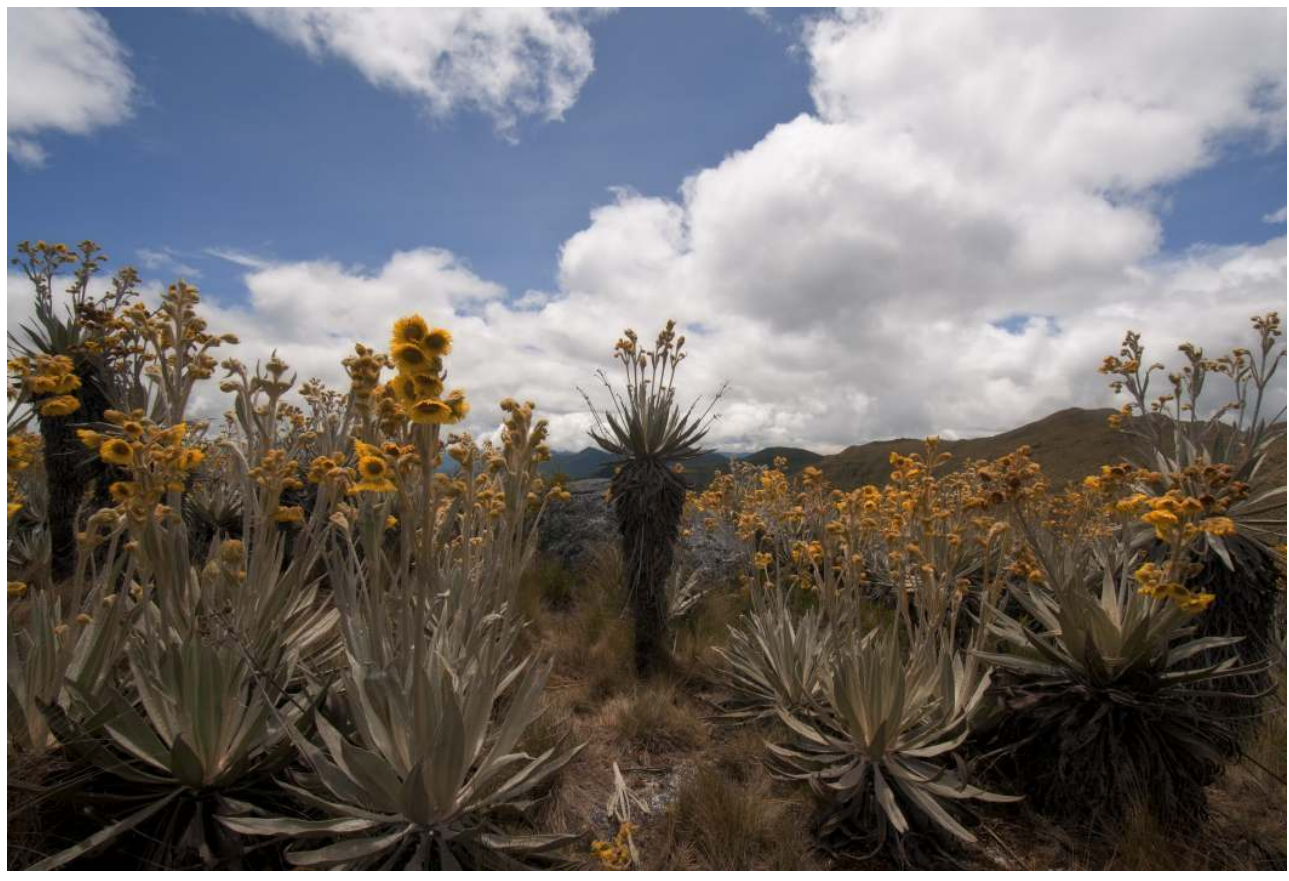

Parque Naatural Chingaza, reservorio de agua de la ciudad de Bogota, 2011-2017

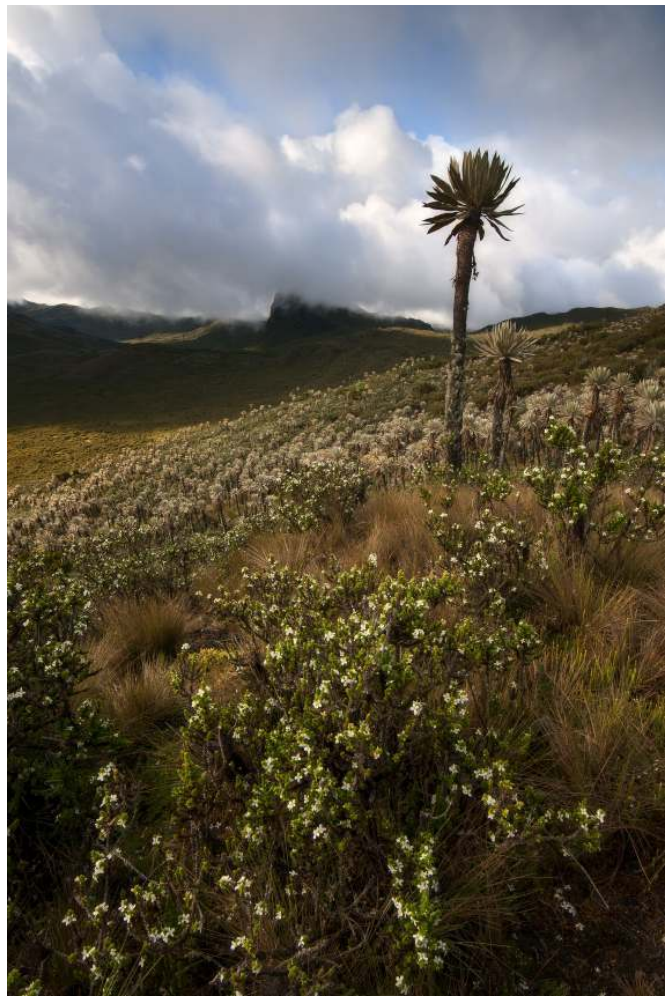


Parque Naatural Chingaza, reservorio de agua de la ciudad de Bogota, 2011-2017

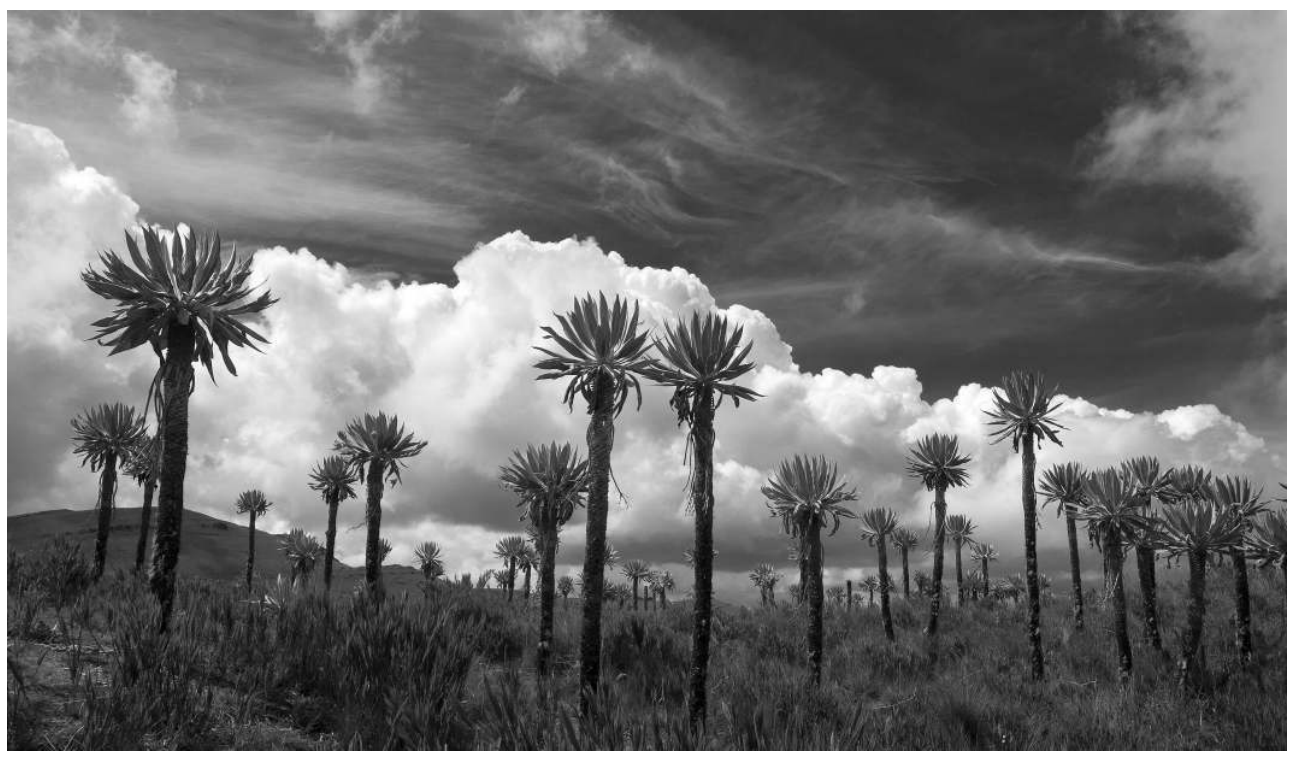

Parque Naatural Chingaza, reservorio de agua de la ciudad de Bogota, 2011-2017

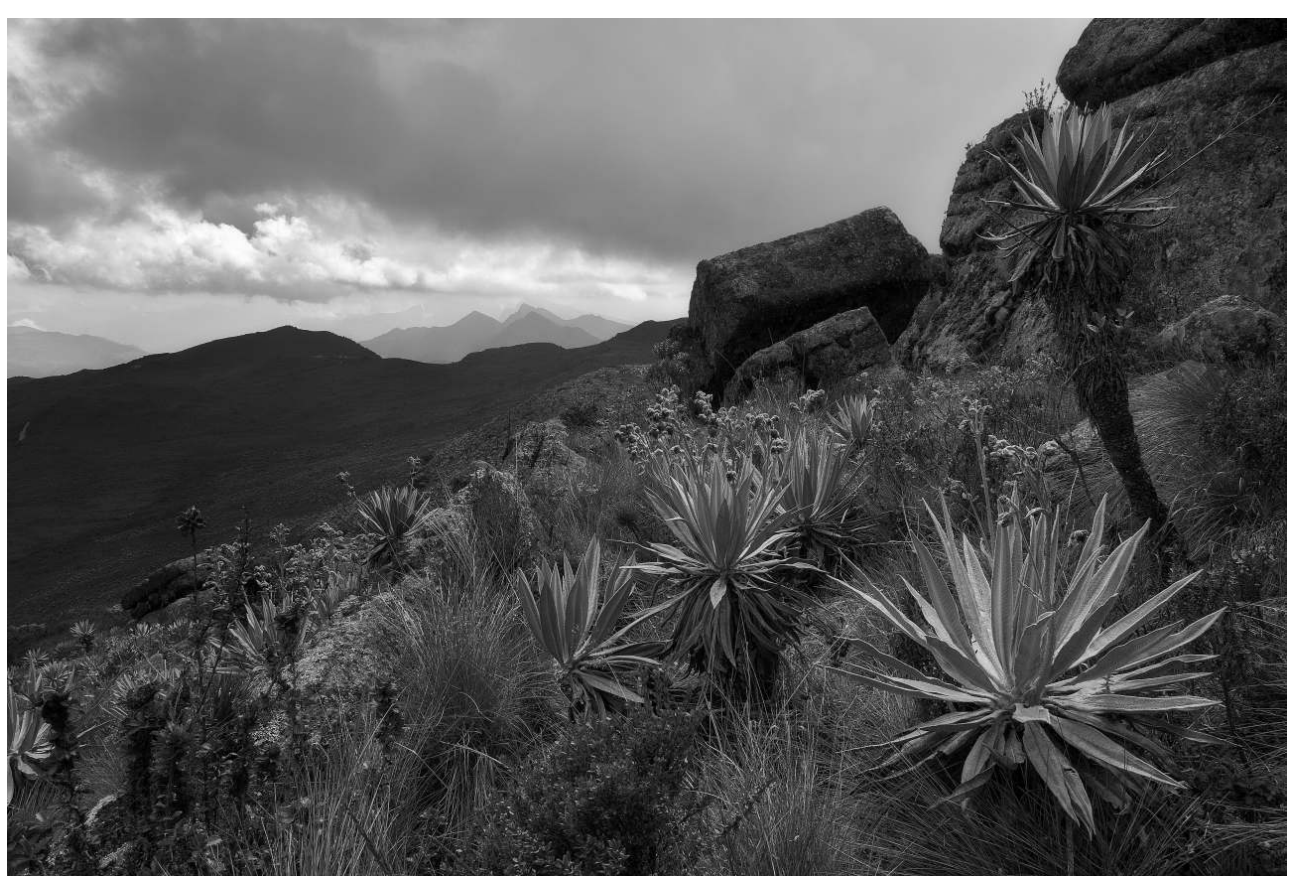


Parque Naatural Chingaza, reservorio de agua de la ciudad de Bogota, 2011-2017

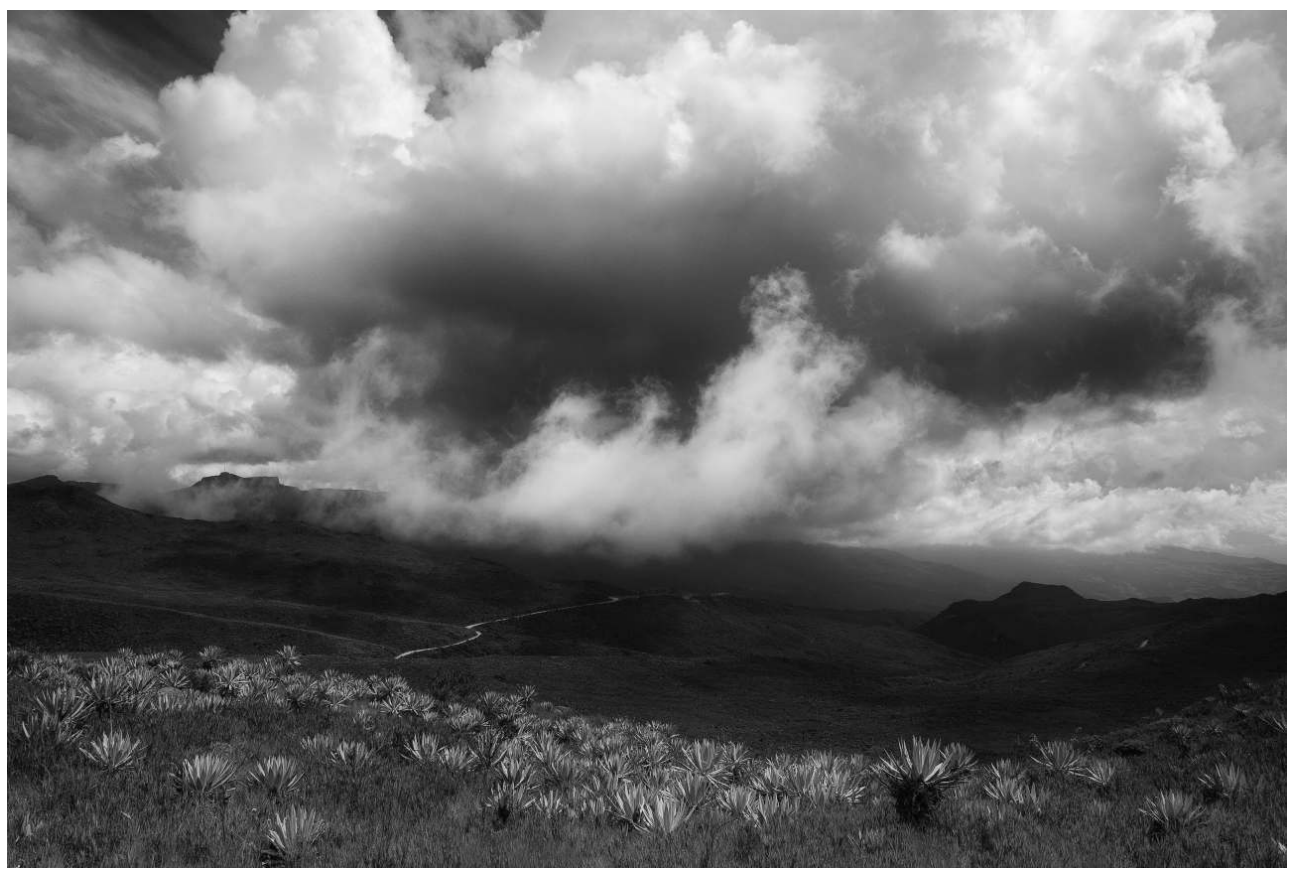

Parque Naatural Chingaza, reservorio de agua de la ciudad de Bogota, 2011-2017

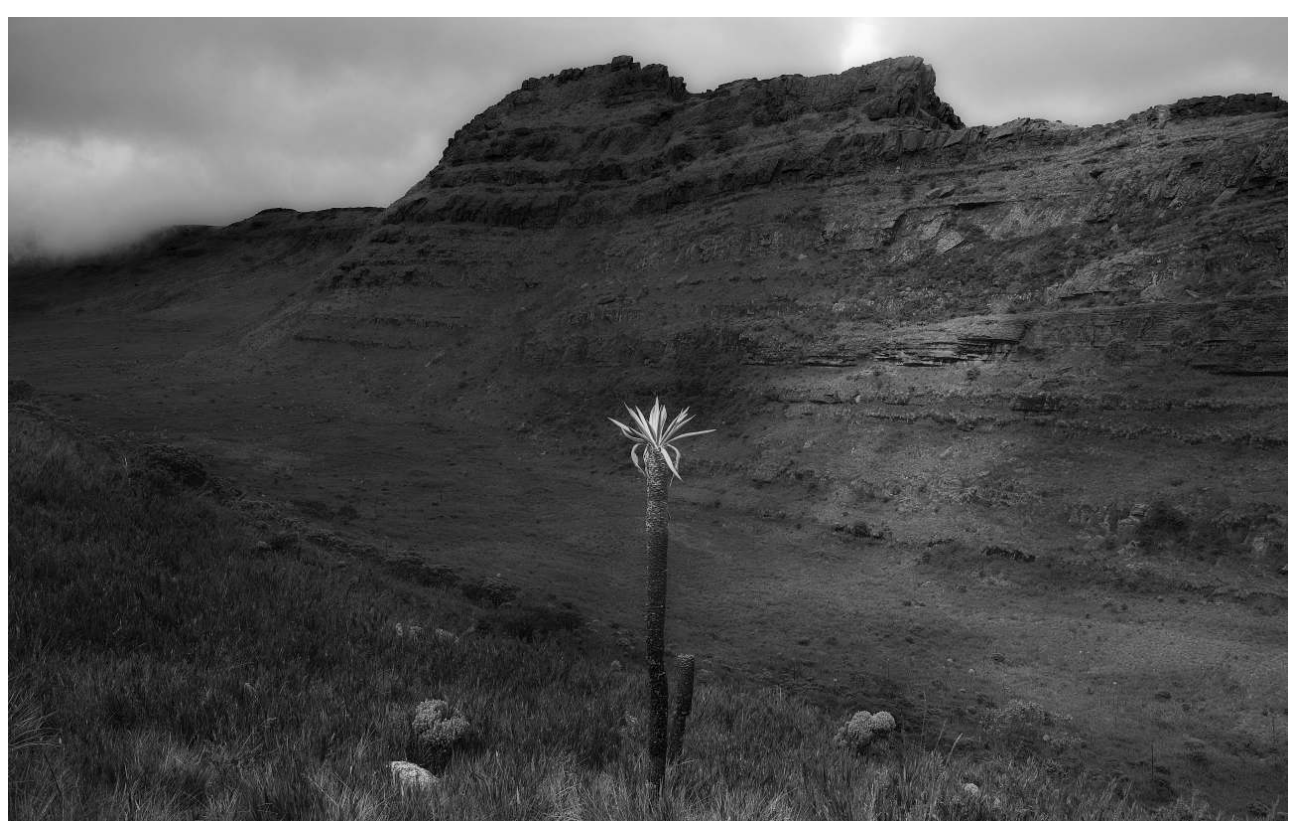


Parque Naatural Chingaza, reservorio de agua de la ciudad de Bogota, 2011-2017

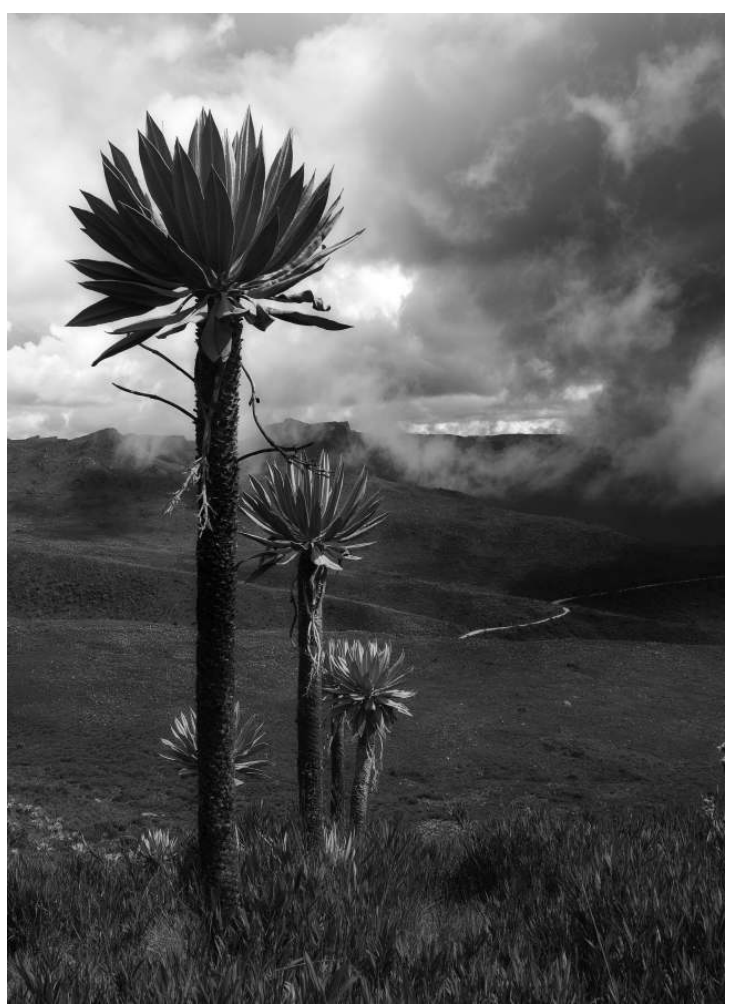

\section{AUTOR}

\section{MIGUEL IRIARTE}

Nació en Sincé Sucre en 1957 y reside actualmente en Barranquilla desde hace 30 años.

Licenciado en Filología e Idiomas de la Universidad del Atlántico, Especialista en Gerencia y Gestión Cultural de la Universidad del Norte; Magíster en Comunicación de la Universidad del Norte. Poeta, publicista, periodista cultural, gestor cultural y catedrático de Semiótica y Comunicación de la Universidad del Norte. 